\title{
La centralidad de la educación en los Discursos de Fichte
}

The Centrality of Education in Fichte's Addresses

\author{
Mariano Lucas Gaudio \\ mgaudio77@yahoo.com.ar \\ (Universidad de Buenos Aires, Buenos Aires, Argentina)
}

\begin{abstract}
Resumen: En el presente trabajo se quiere mostrar que la educación es un tema importante para Fichte, pero que recién se vuelve central en los Discursos a la nación alemana (1807-1808). Para ello, en primer lugar, se analizan distintas obras del filósofo donde la educación aparece relacionada con diversas cuestiones que no son resueltas. En segundo lugar, se expone la centralidad de la formación espiritual en los Discursos como generadora del pueblo y de la nación, que son conceptos ambiguos y a producir. También se contrasta entre la antigua y la nueva educación, y se observa su dimensión moral y religiosa. En tercer lugar, se examina la conexión de la educación con la filosofía verdadera según Fichte.
\end{abstract}

Palabras clave: Fichte; educación; filosofía; pueblo; nación.

\begin{abstract}
In this paper, we want to show that education is an important topic for Fichte, but it only achieves centrality in Addresses to the German Nation (1807-1808). For that reason, in first place, different works by the philosopher - where education appears related to various issues that are not solved are analyzed. In second place, the centrality of the spiritual formation in the Addresses as a generator of the people and the nation - which are ambiguous concepts and to be produced is exposed. Also, there is a contrast between ancient and new education, and its moral and religious dimensions. In third place, Fichte's connection between education and true philosophy is examined.
\end{abstract}

Keywords: Fichte; Education; Philosophy; People; Nation.

\section{Hacia una concepción de la educación}

La primera afirmación que queremos sustentar es que en las primeras obras de Fichte la educación aparece una y otra vez en distintos contextos argumentativos, pero sólo de modo tangencial y subsidiario de otras cuestiones. Coherentemente, recién en los Discursos a la nación alemana (1807-1808) el tema alcanza una centralidad inusitada hasta entonces, precedida por la elaboración de ideas para la fundación de universidades. ${ }^{1}$ En este apartado intentaremos mostrar un panorama sucinto y

1 Un brillante desarrollo sobre el tema se encuentra en el reciente artículo de F. Oncina Coves (2019). Además de rastrear las obras de Fichte no publicadas, Oncina se concentra en la figura del sabio como hilo conductor y afirma que la "filosofía fichteana manifiesta una irrefragable vocación pedagógica" (p. 41). También H. Traub (2011) hurga en las tempranas prédicas de Fichte, a las que analiza como contracara popular de la filosofía, y donde se entrelazan educación y Estado (pp. 139 ss.). Según Traub, las ideas tempranas de Fichte coinciden con sus ideas tardías. Ahora bien, dado que Oncina 
variado, aunque no completo ni que pretenda agotar el asunto, sobre cómo surge la educación en algunas obras de Fichte, subrayando los presupuestos y problemas de esta concepción inicial. En los apartados siguientes nos ocuparemos de la relevancia de la formación en los Discursos, así como de su entrelazamiento con la filosofía, sin entrar en los detalles del plan educativo ni en la problemática de su realización.

En las Lecciones sobre el destino del sabio (1794) el tema de la educación se insinúa con el ideal de perfección o perfectibilidad continua que, desde el imperativo de la concordancia del Yo consigo mismo, ordena someter al No-Yo y formarlo de acuerdo con el Yo (GA I/ 3 29-31, DS 47-49). ${ }^{2}$ Además, este trabajo de la cultura se puede mejorar y, por ende, allanar y facilitar el camino de la perfectibilidad mediante la relación recíproca del “dar y recibir" entre particulares (GA I/3 38-39, 41; DS 79, 83). ${ }^{3}$ De ahí que, al momento de entrar en un estamento determinado, el individuo se halla comprometido a "devolver a la sociedad lo que ha hecho por nosotros" (GA I/3 48, DS 101$) ;{ }^{4}$ es decir, está obligado a poner su formación al servicio de la sociedad, porque sin ella no podría haberse educado y especializado, ni aprovechado todo el desarrollo anterior de conocimientos que llevaron a que las sucesivas generaciones no tengan que empezar desde cero. Claramente esta perspectiva incide en la figura del sabio, que debe y tiene que ponerse al servicio de la sociedad. El sabio cumple la función de "maestro del género humano" (GA I/3 56, DS 119), que en virtud de sus conocimientos históricos y filosóficos no sólo educa para el porvenir, sino también

sitúa el momento clave en 1806-1807, en Ideas para la organización interna de la Universidad de Erlangen y Plan deductivo de un establecimiento de enseñanza superior (p. 45), podría pensarse que contradice nuestra perspectiva inicial, y sin embargo mejor sería considerar ese momento como el fermento previo de los Discursos, en paralelo y complemento con la posición adoptada aquí. En esta misma línea se sitúa el artículo de S. Bacin (2009, pp. 221-222). La figura del sabio, que no es sólo teórica sino también práctica, incluye la cuestión sobre cómo ha de relacionarse con las instituciones, o a través de cuáles vehículos ha de fomentar el progreso de la cultura. En sintonía, K. Taver (2012, pp. 418, 420-421) acepta que el tema de la educación aparece en distintas obras de Fichte, pero logra profundidad y plenitud cuando se articula con el pueblo y la formación de la identidad nacional.

2 Para las obras de Fichte utilizamos las siguientes abreviaturas, según el orden de aparición. Para las obras completas: GA = Gesamtausgabe der Bayerischen Akademie der Wissenschaften, serie/ tomo, página; FSW = Fichtes sämmtliche Werke, tomo, página. Para indicar el número de parágrafo o discurso en algunas obras específicas: SSL = System der Sittenlehre; GNR = Grundlage des Naturrechts; RDN = Reden an die deutsche Nation. Para las traducciones: $\mathrm{DS}=$ Algunas lecciones sobre el destino del sabio; E = Ética; LFA = Lecciones de filosofía aplicada; SES = Sobre la esencia del sabio; FM = Filosofía de la masonería; FDN = Fundamento del derecho natural; $\mathrm{AE}=$ Aforismos sobre educación; $\mathrm{CEC}=$ Los caracteres de la edad contemporánea; DNA = Discursos a la nación alemana. Las referencias completas se encuentran en la bibliografía.

3 En el marco de la "cultura para la libertad", este Geben und Nehmen se conecta con los escritos de revolución de 1793: Zurückforderung der Denkfreiheit (FSW VI 15-16; trad. cast., p. 20) y Beitrag zur Berichtigung der Urtheile des Publicums über die französische Revolution (FSW VI 86-89). Sobre la intersubjetividad incipiente en las primeras obras de Fichte, véase Gaudio, 2017.

4 En Sittenlehre (1798), Fichte problematiza esta cuestión de la formación estamentaria, aclarando que se necesita una educación previa, de base e igualitaria, para luego cada uno poder elegir (y no seguir el mandato familiar o el contexto) el estamento querido: SSL § 19, GA I/5 243-244, E 296. Este tema también está muy presente en la Doctrina del Estado de 1813: LFA 268-269. 
colabora en la visión y en los medios para alcanzar los fines propuestos.

Esta concepción inicial de Fichte sobre la educación contiene algunos problemas. Ante todo, pese a que presupone - ya en la caracterización de la cultura - que la formación en el más amplio sentido tendría que involucrar a todos los particulares de todos los estamentos, se enfoca en un sector determinado, los intelectuales, como el núcleo que impulsa el camino de la perfectibilidad. Es una visión sesgada, que presupone que la elite cultivada y comprometida serviría para el progreso del todo, y de la que se desprende que los restantes sectores de la sociedad tendrían una educación diferenciada, que bien podría seguirse de la división entre lo intelectual y lo manual, o que bien se podría seguir de la conducción de los sabios. También presupone que la educación se da espontáneamente y por el libre juego entre particulares, aunque a la vez requiere de algún tipo de equilibrio o dirección en base a la división social estamentaria. Como se observará en los Discursos, tal sesgo social explica en gran medida el fracaso de la educación anterior y la necesidad de una nueva.

Esta visión de la educación reducida a los doctos se observa en otras obras de Fichte. Por ejemplo, en Sobre la esencia del sabio (1805), que en gran medida amplía y profundiza el perfil del intelectual de las Lecciones, sostiene que el intelectual representa la concordancia entre lo interior y lo exterior, pensar y actuar, y es el protagonista de la educación y de la época: “Aquel tipo de educación y formación espiritual en cada época, mediante el cual esta época espera conducir a los hombres [...], es la formación sabia - y aquel hombre que participa [theilhaftig] de esta formación, el sabio de esa misma época" (GA I/8 64-65, SES 8). El sabio está amalgamado con la época, y así su función será, o bien la de comunicar, o bien la de actuar para transformar lo existente (GA I/8 66, SES 9-10; véase también GA I/8 114, 118 ss.; SES 81-82, 87 ss.; y GA I/8 437, FM 80-81). Acentuado el compromiso social del sabio, se acrecienta asimismo la sugerencia según la cual con ello se resolvería la formación y dirección de la comunidad. En cuanto al cómo de la educación, Fichte oscila entre una cierta confianza en la libertad, el dejar-hacer y el derrame de ilustración y, al mismo tiempo, un control y una planificación sobre la libertad académica, que debería ser amplia, "pero convenientemente calculada" (GA I/ 8 110, SES 75). ${ }^{5}$

\footnotetext{
5 En el capítulo sobre el estudiante, afirma: "Nuestra doctrina moral [Sittenlehre] [...] no manda: así, como toda filosofía, también ella se mantiene al interior de la legalidad y necesidad, y meramente describe lo que de ahí se sigue y lo que no se sigue. Si esta doctrina moral pudiera permitirse un deseo al exterior, y esperar un resultado, sería sólo el de extraer la fuente del bien desde las rocas secas y duras" (GAI/8 98, SES 58). En sintonía con esta liberalidad, Fichte sostiene que los profesores universitarios reniegan de la vigilancia y de las obligaciones de los maestros de escuela, GA I/8 104, SES 67. Al mismo tiempo, es muy crítico con la libertad académica, porque si bien la apoya, la asocia con la desconsideración del oficio del estudiante: GA I/8 105, 110; SES 68-69, 76. Sobre este tema controvertido, véase C. Piché (2005, pp. 134-135, 144 ss.), S. Bacin (2009, pp. 225-227).
} 
En Filosofía de la masonería (1802) Fichte también parece suscribir el cultivo de un determinado sector para la formación de la sociedad. Lo peculiar de esta obra reside en que, de un lado, reconoce la formación unilateral en cada uno de los estamentos (GA I/8 423, FM 60-61) y, del otro, propone para la masonería que se encargue de "la formación humana común", "la formación polifacética del ser humano entero" (GA I/8 426, FM 65). Pero curiosamente para ello se tiene que separar de la sociedad, como el genio de la pintura que crea en soledad. En consonancia, el genio moral sólo tiene que actuar bien, y esperar que ese modo de actuar sirva de ejemplo para los demás, sin comunicación ni enseñanza (GA I/8 428, FM 68-69). Llevado a la sociedad particular y cultivada, la colaboración en la formación y en el perfeccionamiento sería entonces indirecta.

En Fundamento del derecho natural (1796-1797) Fichte sigue confiando, como en las Lecciones de 1794, en que la educación se origine en la sociedad. Pese a que la educación constituye una pieza fundamental en la teoría de la interpersonalidad de los primeros parágrafos (GNR \& 3 Cor., GA I/3 347-348, FDN 133-134), y pese a que se esclarece la razón profunda y filosófica según la cual el ser humano debe hacerse a sí mismo y no puede lograrlo sino en comunidad (GNR § 6, GA I/3 375, 379; FDN 162, 166), ${ }^{6}$ la educación aparece recién al final y como un - valga la ironía - apéndice de la familia. En efecto, la educación surge en el marco de los padres que naturalmente acogen al débil y desvalido, esto es, al o a los hijos, procurando su conservación, su formación más completa posible y su elevación a la moralidad. "Sólo los padres tienen una visión global del fin de la educación [...]. Ellos son el juez apropiado [...], son soberanos” (GNR Ap. II § 45, GA I/4 142, FDN 399). El Estado tiene el derecho de exigir que los padres eduquen a los niños, y de controlarlos; incluso puede fundar instituciones educativas públicas, pero no puede obligar a los padres a que manden a sus hijos a ellas (GNR Ap. II, §§ 46, 49-53, GA I/4 142, 144-145; FDN $399,401-402)$. Esta solución a medias denota que en buena medida Fichte continúa creyendo en la espontaneidad formativa de la sociedad. Dicho de manera genérica y en perspectiva, en el Derecho natural Fichte todavía considera que la solidez del Estado se logra con la estructura jurídico-política que abarca también lo social y lo económico, prescindiendo con ello de la dirección de la cultura y de la formación de la nación. Tal prescindencia mutará poco después, en el final de El Estado comercial cerrado (1800) con la introducción del concepto de nación (GA I/7 139; Traducción

\footnotetext{
6 Sobre la base de este esquema de exhortación y reconocimiento, la educación nunca puede ser un acto mecánico de influencia sino siempre una invitación a la actividad libre: M. Altman (2008, pp. 181 ss.). Con ello coincide Ch. Senigaglia (2015, p. 213), aunque como característica general del desarrollo de la cultura. M. Heinz y C. Binkelmann (2012, p. 257) también subrayan el aspecto social y jurídico de la formación como constitutiva de la personalidad y de la libertad, pero bajo la firme separación entre derecho y moral. Para R. Williams (1992, pp. 59-60), en cambio, la educación tiene una connotación primordialmente ética. Y lo mismo sostiene E. Balibar (2011, p. 22) en relación específica con los Discursos.
} 
de cast. pp. 158-159), y en La destinación del hombre (1800) con la necesidad de construir un gran "Sí mismo" (GA I/6 272-277).

En la Ética y con motivo de examinar la figura del docto, Fichte afirma que "es él mismo de manera indirecta un funcionario del Estado, pues es el educador de los que educan al pueblo" (SSL § 18, GA I/5 225, E 280). Pero separa las tareas: el docto tiene, a diferencia de los educadores directos del pueblo, completa libertad. Así, mientras de un lado admite implícitamente que el pueblo tiene que ser educado y que en la formación de los maestros el Estado tendría competencia, del otro absuelve a los doctos de imposiciones o prescripciones, sugiriendo así cierta confianza en la kantiana libertad del espacio público. Ahora bien, aunque separa los roles entre docto y educador, a la vez sostiene que ambos son doctos, quizás sólo con una diferencia de grado o de nivel. Por tanto, la obediencia del educador de base también sería limitada. Y, como en el Derecho natural, Fichte sitúa la educación en el ámbito de la familia y sin la intervención del Estado (SSL § 27, GA I/5 294-299, E 339-343). En coherencia, la educación moral proviene de la interacción recíproca y corresponde a todos los miembros de la comunidad; por ende, por más que se le asigne determinada función al educador del pueblo - por ejemplo, la aclaración de los artículos de fe, o la aplicación de la ley moral a un caso concreto -, "no demuestra, no polemiza", sino que habla “como un consejero” (SSL § 30, GA I/5 306, E 350). Cumple así una suerte de rol testimonial. Lejos de esta perspectiva de la Ética, entonces, se halla una concepción educativa que asuma activamente una función política y formativa de lo social.

Las consideraciones de Fichte sobre la educación analizadas hasta aquí en general sólo asoman hasta la orilla o bordean la cáscara del problema. De todos modos, la cuestión pedagógica subyace desde el comienzo a la misma Grundlage der gesammten Wissenschaftslehre (1794-5), desde la "necesidad" que supone en el lector u oyente para la re-construcción del sistema (GA I/2 253). En efecto, la exhortación iniciática y délfica de pensarse a sí mismo supone un acto originario de libertad irreductible a la demostración o deducción, puesto que sólo a partir de ese acto fundante se siguen determinadas leyes, reglas o pasos deductivos necesarios. ${ }^{7}$ Una vez aceptado el primer paso, lo demás se sigue por consecuencia o por volverse hacia la condición de la condición; de una u otra manera, se sigue con necesidad, de acuerdo con el procedimiento trascendental. Por lo tanto, la libertad y la sujeción a leyes (lo que en otro contexto es la coacción) no se deberían entender como contrapuestas, sino como conciliables.

En otras palabras, la Doctrina de la Ciencia, al igual que la verdad, no puede

7 Esto sucede en varias obras de Fichte: Erste Einleitung § 1, GA I/4 186; Zweite Einleitung, GA I/4 209, 215 ss., 245; Versuch einer neuen Darstellung, GA I/4 275); Wissenschaftslehre nova methodo - Halle, GA IV/2 22, 25; Wissenschaftslehre nova methodo - Krause, GA IV/3 334. 
imponerse, sino que tiene que surgir en el educando, de su propia autoactividad, que se activa en cuanto piensa el pensar y, de este modo, se eleva sobre lo mecánico (GA 1/4 258-259). Tiene que producirse espontáneamente y fundarse en el acto originario de libertad, de manera que la asimetría entre educador y educando sea neutralizada por la simetría de la reciprocidad del actuar desde la libertad. Fichte sostiene que la Doctrina de la Ciencia se hará inteligible cuando se realice un giro radical en la educación, esto es, cuando se proponga a los niños, no ya dirigirlos y convertirlos en instrumentos dóciles y obedientes, sino desplegar en ellos y por ellos la fuerza interior y que ésta sea utilizada por la respectiva voluntad. Luego, cuando en las nuevas generaciones se difunda una educación para la libertad, la Doctrina de la Ciencia será fácil de comprender. En la Segunda introducción dice claramente: "La formación del hombre entero desde su más temprana juventud, éste es el camino para la propagación de la filosofía. La educación se tiene que conformar primero con ser más negativa que positiva", en el sentido de que debe "[limitarse] sólo [a] la acción recíproca con el educando, [y] no [querer ejercer] influencia sobre él”, porque la influencia implica arrancar "la raíz de la autoactividad" y suplantarla con la predisposición "a esperar el impulso de afuera” (GA l/4 259).

Para Fichte, entonces, la acción recíproca tiene que primar en la mayor medida posible por sobre la influencia, que ha de ser excepcional y sólo para cuando sea imposible aplicar la primera. La recreación de simetría se ofrece como esquema pedagógico para una relación asimétrica (pues en la relación subsisten los roles de educador y educando) donde, no obstante, las dos partes son libres. Y son libres porque, sin actividad, no hay aprendizaje auténtico, mientras que la espera pasiva tiende a apagar el brote de libertad. En rigor, no hay educación genuina sin libertad, que es la fuente desde la cual se activa la razón para operar luego como un proceso mecánico-deductivo.

En los Aforismos sobre educación (1804) Fichte presenta una tesitura similar: "Educar a un hombre significa darle la oportunidad de hacerse por sí mismo maestro y autodominador absoluto de toda su fuerza" (AE 121); es decir, significa ayudarlo a hacerse racional $y$, por consiguiente, a constituirse tal como debe ser. En cambio, cuando la educación se ejerce como influencia o adoctrinamiento, el hombre queda atrapado y condenado en los límites. Al igual que en Ética, la educación existente parece un salvavidas de hierro; en cambio, la educación que apuesta a desarrollar la fuerza interior del hombre, busca liberarlo y capacitarlo "para un crecimiento viviente desde sí mismo" (AE 122). La muerte equivale a la absolutización del límite, la vida a la superación, crecimiento y autorrealización. Tales aspectos serán muy relevantes en los Discursos.

Ahora bien, si se reúnen y sintetizan todas estas variadas consideraciones en una suerte de pieza única, se puede señalar una serie de aspectos significativos: la 
visión sesgada sobre la educación diferenciada según sectores, la confianza (mayor o menor) en el espontaneísmo, la ambigüedad entre el compromiso y la libertad o separación del sabio, y entre el vínculo y el carácter directriz, el auto-hacerse del ser humano mediado por la acción recíproca intersubjetiva, la potestad soberana de los padres y el rol pasivo del Estado, el educador del pueblo que se distingue del docto y que parece funcionario pero sólo educa indirectamente, la articulación entre autoactividad y necesidad, el diagnóstico negativo sobre la educación existente como contraste para una visión propositiva, y las nociones de fuerza interior y crecimiento vital. La gran mayoría de estos problemas y presupuestos son recogidos y debatidos en los Discursos.

\section{La relevancia de la formación espiritual}

En los Discursos a la nación alemana (1808) la educación constituye, si no "el” tema por excelencia, al menos uno de los puntos más importantes. No sólo porque Fichte analiza la educación en el comienzo, en el desarrollo y hacia el final de la obra - es decir, no sólo porque atraviesa los discursos como una problemática a explicitar una y otra vez -, sino también porque se conecta con las ramas particulares del saber: con el derecho y el Estado, con la ética, con la religión y, en especial, con la filosofía primera. Y se conecta ocupando una función crucial, como una instancia absolutamente necesaria e insoslayable para el desenvolvimiento de cada uno de los ámbitos e incluso para la realización de los conceptos o Ideas que denotarían - de acuerdo con la clasificación de Los caracteres de la edad contemporánea (GAI/8 198, CEC 24-27) que retoma en los Discursos (RDN, GA I/10 99, 104-105; DNA 39, 49-50) - el pasaje de la época del egoísmo (la tercera) a una etapa plenamente racional.

Ahora bien, el concepto de educación en los Discursos de Fichte está directamente relacionado con otros dos conceptos, pueblo y nación, que contienen una serie de dificultades al momento de ser definidos. Brevemente, el pueblo, que involucra a un múltiple de individuos que coexisten en un mismo territorio, para Fichte es tanto el ámbito del despliegue máximo del egoísmo (RDN I, GA I/10 109, DNA 54), como el reservorio ideal e identitario para canalizar la educación nacional, dado que toda formación proviene de él (RDN I, GA I/10 115, DNA 61). Mientras que lo primero acentúa el rasgo crítico hacia la propia época y la necesidad de transformar la situación existente, lo segundo expresa un diagnóstico optimista de confianza en la superación o auto-aniquilación del egoísmo. Pero esta metamorfosis ¿se produce naturalmente, por el curso mismo de los hechos? Si el pasaje del egoísmo al vínculo moral fuera resultante de la mera socialización, entonces la educación ocuparía un lugar subsidiario o colaborativo. Sin embargo, el énfasis que Fichte coloca en el plan educativo sugiere lo contrario: que el egoísmo produce más egoísmo y que, lejos de 
aniquilarse, tiende a la destrucción de cualquier organización social, pues el egoísmo siempre presupone la escisión entre beneficiados y perjudicados y de ella se deduce el beneficio que algunos puedan obtener del perjuicio de otros.

El otro concepto implicado en la educación, la nación, se relaciona principalmente con la lengua y, de modo secundario y menor, con el suelo. Según Fichte la vinculación a través del suelo responde a un dato empírico y no-decisivo respecto de la nacionalidad. La clave, entonces, reside en la lengua, que sí parece ser un motivo más profundo de vínculo entre los individuos. Por un lado, la lengua forma a sus hablantes (RDN IV, GA I/10 145-146, DNA 98), habla a través de ellos; por otro, no es más que un instrumento sensible para cristalizar en cierta medida lo suprasensible (RDN IV, GA I/10 147, DNA 99). ${ }^{8}$ En este segundo sentido, lo decisivo de una lengua para mantener su vitalidad está en la captación y exposición de lo inteligible, así como en la fluidez y continuidad de lo originario en sus hablantes. Pero todo esto no alcanza para definir lo que Fichte se propuso como meta, a saber, la especificidad de lo alemán. Antes bien, las caracterizaciones se esfuman en la generalidad, o quizás también en la contienda más coyuntural entre el invento de la alemanidad frente al extranjero francés invasor. ${ }^{9}$ Cualquier otro pueblo podría aducir para sí la misma vitalidad que Fichte encuentra en la lengua alemana. La diferencia se desplaza, por tanto, hacia la formación espiritual, y esto es precisamente la filosofía. De ahí que finalmente no importe para Fichte dónde haya nacido el individuo, ni qué lengua hable, sino que para ser alemán sólo tiene que creer en la formación continua, espiritual y libre (RDN VII, GA I/10 195-196, DNA 153). Por consiguiente, la alemanidad se ha vaciado de rasgos específicos o de un contenido distintivo, para convertirse en un concepto o Idea a realizar.

Así la disputa entre los modelos de pueblo, el nacional y el extranjero, debe decidirse en la filosofía primera, que ha de ofrecer un camino para concretizarse en un plan educativo. Más aun, las ambigüedades de los conceptos de pueblo y nación se explican tanto por la posibilidad de atribuirles contenidos diversos, ambiguos, contrarios o nunca concluyentes, como por la centralidad de la formación espiritual que coloca a esos conceptos como fines o metas a plenificar por la misma educación. En otras palabras, pueblo y nación cobran fuerza y sentido a partir del par educación-filosofía.

En los Discursos educación y filosofía están fuertemente entrelazadas. Pero desde el comienzo se observa en la educación un tenso contraste que en alguna medida remite a la cuestión de la articulación entre libertad y necesidad. De acuerdo con el diagnóstico de la época, dado que el egoísmo está al borde de su

8 Sobre el lenguaje en Fichte, véase T. S. Hoffman (2019).

9 Sobre el contexto de los Reden: U. Baumann (2011, pp. 177-179), J. Rivera de Rosales (2015, pp. 125 ss.). 
aniquilación, para Fichte hay que reconstruir el débil vínculo social basado en el temor y la esperanza, generando un vínculo moral de compromiso - de aprobación o consentimiento [Billigung], o de su contrario - frente a lo que sucede en el entorno y en las relaciones. El Selbst que en el egoísmo se vuelve y cierra sobre sí, mediante el ojo interno se puede abrir al entorno y asumir lo propio y lo ampliado como formando parte de lo mismo e inseparablemente conectado. Fichte sostiene que con la formación del ojo interno se halla un medio seguro y único para recuperar una nación que ha perdido su autonomía e influencia en los asuntos públicos. La educación aparece así como un "medio de salvación” (RDN I, GA I/10 112, DNA 58) para crear un nuevo Selbst nacional, para gestar una vida totalmente nueva. Sin embargo, para ello se requiere un cambio completo en su esencia.

La nueva educación nacional se erige en contraposición con la educación anterior. Basada en representaciones y amonestaciones éticas que no pudieron remover el impulso natural del egoísmo, en maneras de hablar y colocar en la memoria imágenes pálidas que no lograron darle vivacidad al orden moral del mundo, la educación anterior según Fichte se ha mantenido lejos de formar la raíz del movimiento vital efectivo, de educar al hombre en su conjunto y en toda su profundidad. Por lo tanto, la nueva educación tiene que llegar a la raíz y formar lo más constitutivo y personal del educando (RDN I, GA I/10 113-114, DNA 58-59), “tiene que poder determinar y formar segura e infaliblemente según reglas el movimiento y el impulso vital efectivo de sus educandos" (RDN II, GA I/10 117, DNA 65).

Aquí Fichte se formula una objeción: ¿qué más se puede hacer que mostrar lo justo y amonestar al educando a que lo siga de acuerdo con su voluntad libre? Y responde: precisamente el primer gran error de la educación anterior reside en que no forma la voluntad, la raíz fundamental y propia del ser humano. En consonancia, la nueva educación "tendría que consistir en [...] aniquilar totalmente la libertad de la voluntad, y contrariamente producir en la voluntad la necesidad estricta de las resoluciones y la imposibilidad de lo contrapuesto" (RDN II, GA I/10 118, DNA 66). Las "resoluciones" [Entschliessungen] se explican por contraste con la educación anterior, que dejaba a la voluntad libre de permanecer indecisa y oscilante entre lo bueno y lo malo. Dicho más francamente aun: "Si quieres ser capaz de algo sobre él [el hombre], entonces tendrías que hacer algo más que meramente hablarle; tendrías que constituirlo, constituirlo de modo tal que jamás pueda querer nada distinto de lo que tú quieres que él quiera”. Y poco más abajo: “La nueva educación tiene que producir esta voluntad firme y no más oscilante según una regla eficaz [wirksamen], segura y sin excepción; ella tiene que crear [erzeugen] con la necesidad la misma necesidad que se ha propuesto" (RDN II, GA I/10 119, DNA 67).

¿Cómo se compatibiliza esta propuesta con la libertad? ¿Cómo no asociar la nueva educación con un procedimiento mecánico, con una suerte de coacción para 
determinar la voluntad? La educación anterior parece haber pecado de excesivo liberalismo. Ciertamente se podrían poner muchos reparos a esta objeción y defender la posición de Fichte; por ejemplo, afirmando que, al no llegar a la raíz de la voluntad, la educación anterior sustituía la libertad por el arbitrio; o que la formación de la necesidad de la voluntad no es incompatible, sino coherente, con la libertad; o que se trata de menores de edad cuya racionalidad aún no ha despertado; o simplemente que en la formación no hay un arte seguro e infalible. Desde el punto de vista argumentativo, Fichte busca garantizar que la nueva educación conduzca necesariamente a un nuevo orden de cosas, que el menor de edad se active racionalmente. En última instancia, quiere intervenir en la decisión de la auto-determinación y de la voluntad. Pero en este punto soberano no pueden coexistir libertad y necesidad externa, o auto-actividad e influencia, sino que deben unificarse; entonces, ¿cuál contiene a cuál?

Fichte no se plantea explícitamente este problema, que es muy similar a la coacción que presupone el consentimiento y que imbrica lo político con lo pedagógico, ${ }^{10}$ sino que prosigue y coloca justamente a la autoactividad en el centro de sus consideraciones. En efecto, afirma que hay que educar el amor, más precisamente el amor hacia el bien y hacia el conocimiento. La proyección de una imagen que contenga un estado de cosas signado por el bienestar (un estado de cosas inexistente, pero cuya naturaleza motiva la realización), permite despertar la libertad y la creatividad. La facultad de proyectar imágenes apunta no a las copias (a los casos particulares, a la mera reproducción), sino al modelo o arquetipo [Vorbild], a lo universal, a las leyes, y a la producción de lo nuevo; es decir, potencia la creatividad, desarrolla la autoactividad del educando, y de esta manera engendra conocimiento y retroalimenta el deseo de aprender (RDN II, GA I/10 119-122, DNA 68-70).

En sintonía con la distinción entre teoría y práctica, la nueva educación tiene que formar, como partes constitutivas del ser humano, el entendimiento y la voluntad (RDN III, GA I/10 134 ss., DNA 85 ss.). Con el conocimiento solo no basta: hay que formar moralmente la voluntad. Y para ello hay que conducir el Selbst o amor elevado hacia sí mismo, a un orden de cosas totalmente nuevo, donde la actividad espiritual no busque el goce sensible, sino la actividad por sí misma, y donde la voluntad pura sea lo suficientemente firme como para contener un eventual rebrote

\footnotetext{
10 La presuposición de consentimiento en la coacción se observa ya en GNR §§ 13-15 (GA I/3 423-432, FDN 213-222), porque el mecanismo de coacción que pretende ser infalible opera sobre voluntades. La similitud entre consentimiento y coacción, así como la inseparabilidad entre lo político y lo pedagógico, se cristalizan en LFA 125 ss., 134 ss. De todos modos, aquí en los Discursos también hay aspectos para ver la conexión, porque la política (Staatskunst) enlaza el bienestar personal con el interés comunitario, sólo que de una manera exterior y capaz de convivir con la maldad, el egoísmo o la exacerbación del bienestar personal y sensible; por eso la nueva educación tiene que atacar la raíz de la voluntad y formar seres morales desde lo más profundo de su interioridad. RDN II, GA I/10 119, DNA 67-68.
} 
de egoísmo. La imagen de este orden social inspira la organización comunitaria de la escuela, donde la sumisión al deber va desde la instancia penal hasta el servicio desinteresado del individuo hacia la comunidad (RDN II, GAI/10 126-130, DNA 74-77). Se observa aquí la primacía de la religión sobre la ética (como en Los caracteres: GA I/8 378-380, CEC 198-200):

Esta educación ahora no aparece más, como en el comienzo de nuestro discurso de hoy, meramente como el arte de formar al educando hacia la eticidad pura, sino que más bien brilla como el arte de formar al hombre absoluta y completamente como hombre total (RDN III, GA I/10 114, DNA 85).

La intelección de este orden superior proviene tanto de la formación como de la autoactividad, e implica una dimensión ético-religiosa donde el educando comprende que la vida superior se muestra en múltiples configuraciones y, no obstante, es siempre Una y la misma y, por consiguiente, que su propia vida es la de un miembro de la cadena eterna de la revelación de la vida divina, que posee un contacto inmediato con Dios y con la vida que emana de él, y que la religión que consiste en que nuestro vivir en Dios debe dirigir la nueva época (RDN III, GA I/10 132-133, DNA 82).

En perspectiva, la concepción educativa de Fichte parte del conocimiento básico, se eleva hacia el orden moral y desemboca en la vida divina. Pero el elemento clave, el estímulo y la incitación a la autoactividad en el educando, así como la tensión entre libertad y necesidad, requieren una visión filosófica tal que, además, recoja y supere las instancias anteriores.

\section{La filosofía en la educación}

Como señalamos, lo que define y diferencia en última instancia a la nación y lo que ha de orientar la nueva educación es la filosofía o formación espiritual. La cuestión concierne a la peculiaridad de la filosofía alemana en contraste con la extranjera. Ahora bien, cabe enfatizar que "alemana" y "extranjera" no son connotaciones específicas que refieren a un conjunto de individuos, porque "alemán" no se corresponde ni con el que vive en un lugar ni con el que habla una lengua, sino con los que comparten una manera de pensar. Por tanto, “alemán” y "extranjero" son referentes difusos y vaciados de sentido, y hay que considerarlos en adelante como entre comillas o como maneras de hablar, puesto que se relacionan específicamente con la contienda última/primera, la filosófica, para mostrar la confrontación entre dos sistemas explicativos, dos visiones que se parecen en algunos aspectos pero contienen una diferencia fundamental.

Según Fichte, la filosofía alemana se erige por oposición a la filosofía extranjera, cuyo déficit principal consiste en que no se enlaza con lo Absoluto, con algo último, firme, constante e inmodificable; o también en que traza un límite 
último impenetrable y legitima un Ser fijo y muerto. Pese a la actual interpolación de extranjerismo, prosigue Fichte, la filosofía alemana quiere fundamentación, forma científica, unidad, realidad, esencia; y agrega: "no [quiere] mera manifestación, sino una manifestación en la que se manifieste el fundamento de esta manifestación" (RDN VII, GA I/10 184, DNA 142). La verdadera filosofía alemana, entonces, se introduce en y atraviesa el núcleo de la vida divina, la vida Una y pura, la vida sin más, la vida eterna y única que permanente e infinitamente "se cierra y se abre de nuevo" (RDN VII, GA I/10 185, DNA 143). Sólo así se presenta un Ser o Algo último, y sólo así se construye una filosofía originaria y auténticamente alemana. ${ }^{11}$

De manera consciente o inconsciente, el sistema de pensamiento repercute en las restantes visiones de una época. Fichte ejemplifica esta captura respecto de la política, y luego eleva el contrapunto entre la filosofía alemana y la extranjera hasta la metafísica. En cuanto al sistema de gobierno, el pensamiento extranjero ha desarrollado un arte mecánico grande y artificial, donde el individuo está obligado a servir al todo y es una pieza reemplazable. Esta gran maquinaria funciona necesariamente, nada la detiene, exhibe una apariencia de superioridad y conduce hacia la monarquía más fuerte, donde todo miembro está irresistible e inevitablemente coaccionado a hacer lo que hace bajo un esquema superior / inferior (mandato / obediencia). Luego, ¿qué sucede con la cima de la máquina? ¿Cómo se mueve el último resorte y, cómo se lograría que siempre tenga que querer el derecho? Aquí surge el asunto fundamental, el punto soberano de la política, que Fichte trata con una disyunción sobre el origen del movimiento del mecanismo: o bien el móvil proviene de una fuerza que está en el resorte último, o bien proviene de una fuerza que no está en él, sino en el todo, y que es independiente de él (RDN VII, GA I/10 186-187, DNA 144-145).

Las dos opciones son problemáticas. Si la fuerza proviene del resorte con independencia del todo, entonces no hay mecanismo; pero, al revés, si el resorte no se obliga a sí mismo, entonces no hay movimiento, y el mecanismo se explica por una fuerza oculta y desconocida que excede los cálculos del sistema. Además, ambas posibilidades comparten una limitación significativa, a saber, que sólo se ocupan de la coacción y descuidan todo lo demás. La crítica se condice plenamente con la visión unilateral e insuficiente del Estado como sistema coactivo que Fichte ya despliega y supera en Los caracteres con el concepto de Estado racional o absoluto (GA I/8 307-311, CEC 129-132). La crítica también se asemeja al reproche a la educación anterior según el cual no va más allá de lo superficial y exterior. Más precisamente, la educación en la política extranjera sólo se preocupa por el príncipe, y por ello

11 De acuerdo con la sugerencia del/la evaluador/a anónimo/a, este Discurso VII de los Reden, que es intensamente especulativo, podría ser complementado y articulado con la Wissenschaftslehre de 1807; por razones de espacio y delimitación, dejamos constancia y agradecemos el señalamiento, para que sea retomado y desarrollado en otro trabajo. 
recae en el sesgo de educar sólo a los estamentos cultos. Esta visión de la política centrada en la coacción, concluye Fichte, no se corresponde con los alemanes (RDN VII, GA I/10 187-188, DNA 145-146).

La política alemana coincide con la extranjera en querer firmeza, seguridad e independencia de la naturaleza, pero se distingue en que no sustenta una cosa como lo primero y desde lo cual se constituye el espíritu como un segundo miembro, sino que el espíritu es lo más alto y único, "el resorte eternamente movible y viviente desde sí mismo, que ordenará y moverá continuamente la vida en sociedad" (RDN VII, GA I/10 188, DNA 146). No casualmente Fichte se dirige a los jóvenes y a las futuras generaciones que surgirán con la nueva educación, lo que reafirma que pueblo y nación son conceptos a construir y realizar, y cuya diferencia clave con la educación anterior y con el extranjerismo reside en que la nueva educación no ha de ser sesgada (para el príncipe o para el sector cultivado solamente), sino que ha de abrazar la llanura de todos en igualdad.

Mientras que la filosofía extranjera considera la libertad como oscilación indecisa entre posibilidades iguales, y con ello se queda en el vestíbulo de la vida real, la filosofía alemana va hasta lo profundo y considera la decisión de la voluntad como algo primero, como fundamento, existente por sí mismo sin más; y éste es para Fichte el verdadero significado de la libertad. En cuanto al contenido interno, prosigue, se dan dos casos en manifestación: o bien está separada de la esencia, o bien la esencia se manifiesta en ella (RDN VII, GA I/10 191, DNA 148-149).

En el primer caso, la manifestación como tal significa una separación de y oposición a la esencia; no es lo primero, libre y originario, sino que resulta de la ley de la manifestación. La manifestación es copia y espejo de lo interior. Según la ley primera de la manifestación, lo Uno se descompone en lo múltiple y cada particular está determinado por todos los restantes.

La ley fundamental y primera de la manifestación [...] es ésta: que ella se disocia [zerfalle] en un múltiple, que en una cierta perspectiva es lo infinito, y en otra perspectiva determinada es un todo cerrado; un todo cerrado de lo múltiple en el cual todo particular está determinado por todos los restantes, y de nuevo todos los restantes están determinados por este particular (RDN VII, GA I/10 192, DNA 149).

En este esquema, la decisión de la voluntad aparece condicionada por el entramado $\mathrm{y}$, por tanto, no autónoma, ni originaria, sino como mera consecuencia (RDN VII, GA I/10 149, DNA 150).

En el segundo caso, si la esencia se vincula inmediatamente con la manifestación, dice Fichte, sucede lo mismo que antes - el particular está determinado por y es consecuencia del todo -, pero no se agota en ello, sino que hay algo más, precisamente un "más" [Mehr] que, de un lado, se sustrae a la explicación de la manifestación y, del otro, deviene visible. Este “más” está por encima de la ley, no 
resulta de ella; se trata de una instancia verdaderamente primera, que es lo que es por sí misma, originaria y libre. El "más" se visibiliza sucesivamente y más allá de la manifestación, al infinito; se visibiliza como un "más" simple e inmodificable que, al devenir visible, crea lo infinito y todo lo que parece manifestarse en él. Cuando este "más" se visibiliza en uno y el mismo querer, se visibiliza la esencia, la única esencia verdadera, la divina (RDN VII, GA I/10 193, DNA 150-151).

En consecuencia, la libertad para Fichte admite dos sentidos: en un sentido inferior, consiste en oscilar entre distintas posibilidades; en un sentido superior, en elevarse sobre la cadena de la manifestación y captar la propia vida en su devenir inmediato de la vida divina y, por ende, creer en la libertad en sí y en otros (RDN VII, GA I/10 193-194, DNA 151). En aquel “más” radica la posibilidad de abrir incluso el ámbito de posibilidades en que se realiza la libertad y, en consonancia, mantener vital y en devenir el flujo que proviene de Dios. Por eso, la auténtica diferencia entre los alemanes y el extranjero consiste en la creencia en algo primero y originario en los hombres mismos; la creencia en la libertad, en la infinita mejorabilidad y en el progreso eterno, donde todos viven creativamente y produciendo lo nuevo, viven en el flujo de la vida originaria y son hombres originarios, un pueblo originario o pueblo sin más (RDN VII, GA I/10 195, DNA 152).

En suma: "Esta filosofía alemana se eleva realmente y mediante el acto de su pensar [...] hasta el invariable «más que toda la infinitud», y encuentra únicamente en esto el Ser verdadero" (Un Ser que no es lo fijo y muerto, ni lo trascendente, sino devenir creativo, amplitud de posibilidades, etc.). "Ella ve el tiempo, la eternidad y la infinitud, en su surgimiento desde el aparecer y devenir visible de aquello Uno que es en sí invisible y que se capta correctamente sólo en esta visibilidad suya" (Es decir, esta filosofía va hasta lo último/primero, y lo capta y expresa en sintonía con lo visible, la manifestación). "Según esta filosofía, la infinitud ya es nada en sí, y no le corresponde absolutamente ningún Ser verdadero. Ella es exclusivamente el medio en donde lo único que existe y que es sólo en su invisibilidad, deviene visible" (RDN VII, GA I/10 196, DNA 153).

\section{Consideraciones finales}

La temática de la educación aparece esporádicamente en distintos contextos específicos de la obra de Fichte, hasta que en los Discursos alcanza una centralidad crucial, porque afecta a todos los ámbitos específicos y se estrecha con la filosofía. Ya no se trata de un tema subsidiario al progreso de la cultura, al mejoramiento social, a un mandato moral o a la transmisión de la Doctrina de la Ciencia; en los Discursos la formación espiritual es no sólo condición constitutiva del pueblo y de la nación, sino también expresa el punto más alto del filosofar, el modo de concebir 
la vida divina. Precisamente esta noción de un Absoluto que se cierra y se abre, que se visibiliza y es en sí invisible (pero que no por ello se vuelve un Otro inaccesible), que está en devenir manifestación y encarnación en imagen y esquemas, explica y a la vez atrae la realización de un nuevo estado de cosas, y semejante transformación no se podría concebir ni producir sin una nueva educación y, en consonancia, sin una filosofía verdadera.

En términos generales, tanto el marco general de la formación espiritual como el diseño más específico del plan educativo tienen para Fichte la finalidad de subsanar una serie de dualismos: la elite cultivada y el pueblo llano, la teoría y la práctica (o el entendimiento y la voluntad, o lo intelectual y lo manual), la vida auténtica y la vida aparente, la organicidad o compromiso social y la posibilidad de transformar la realidad, etc. La función del "más" especulativo consiste en abrir un punto de fuga tal que, manteniendo el entramado de lo múltiple en Uno, a la vez habilite un devenir, una dinámica capaz de vincular y transformar. Pero este movimiento no podría suscitarse sin el juego de la relación simétrica y asimétrica que caracteriza a la educación, es decir, sin una relación que equipara posiciones y va más allá bajo el signo común de la libertad.

Mientras que en las anteriores obras la problemática de la educación surge en conexión con otras cuestiones y como un tema aún a desarrollar, en los Discursos se revela central no sólo por la insistencia de Fichte, o por la necesidad de producir efectivamente el pueblo y la nación; y no sólo porque se articula con todas las disciplinas, sino también porque en la educación (o la filosofía, la formación espiritual), y únicamente mediante ella, se realiza la amalgama social y política lo suficientemente estable como para asegurar el mejoramiento moral, y porque ese proceso justamente expresa el devenir de la vida divina.

\section{Referencias}

Fuentes, traducciones y abreviaturas:

\section{Obras completas de Fichte}

Fichte, J. G. (1962 ss.). Gesamtausgabe der Bayerischen Akademie der Wissenschaften. Hrsg. R. Lauth, H. Jacob, M. Zahn, y otros. Stuttgart: Fromman. Indicamos: serie / tomo y página. [GA]

Fichte, J. G. (1971). Sämmtliche Werke. Hrsg. I. H. Fichte. Berlín: W. de Gruyter. Indicamos tomo y página. [FSW]

\section{Obras y traducciones de Fichte}

Fichte, J. G. (1793). Zurückforderung der Denkfreiheit. En FSW VI 1-35. 
Fichte, J. G. (1793). Beitrag zur Berichtigung der Urtheile des Publicums über die französische Revolution. En FSW VI 37-288.

Fichte, J. G. (1794). Einige Vorlesungen über die Bestimmung des Gelehrten. En GA I/3 23-74.

Fichte, J. G. (1794-5). Grundlage der gesammten Wissenschaftslehre. En GA I/2 249451.

Fichte, J. G. (1796 ss.). Wissenschaftslehre nova methodo - Halle. En GA IV/2 17-266.

Fichte, J. G. (1796-7). Grundlage des Naturrechts nach Principien der Wissenschaftslehre. En GA I/3 313-460, GA I/4 5-165. [GNR]

Fichte, J. G. (1797). Erste Einleitung in die Wissenschaftslehre. En GA I/4 183-208.

Fichte, J. G. (1797). Zweite Einleitung in die Wissenschaftslehre. En GA I/4 209-269.

Fichte, J. G. (1798). Versuch einer neuen Darstellung der Wissenschaftslehre. En GA I/4 271-281.

Fichte, J. G. (1798). Das System der Sittenlehre. En GA I/5 21-317 [SSL]

Fichte, J. G. (1798-9). Wissenschaftslehre nova methodo - Krause. En GA IV/3 323523.

Fichte, J. G. (1800). Die Bestimmung des Menschen. En GA I/6 189-309.

Fichte, J. G. (1800). Der geschlossene Handelsstaat. En GA I/7 38-141.

Fichte, J. G. (1802). Philosophie der Maurerei. Briefe an Konstant. En GA I/8 409462.

Fichte, J. G. (1804-5). Die Grundzüge des gegenwärtigen Zeitalters. En GA I/8 191396.

Fichte, J. G. (1805). Ueber das Wesen des Gelehrten. En GA I/8 59-139.

Fichte, J. G. (1807-8). Reden an die deutsche Nation. En GA I/10 99-298. [RDN]

Fichte, J. G. (1976). Los caracteres de la edad contemporánea. Traducción de J. Gaos. Madrid: Revista de Occidente. [CEC]

Fichte, J. G. (1984). Discursos a la nación alemana. Traducción de L. Acosta - M. Varela. Bs. As., Orbis - Hyspamérica. [DNA]

Fichte, J. G. (1986). Reivindicación de la libertad de pensamiento. Traducción de cast. F. Oncina Coves. Madrid: Tecnos.

Fichte, J. G. (1991). El Estado comercial cerrado. Traducción de J. Franco Barrio. Madrid: Tecnos.

Fichte, J. G. (1994). Fundamento del derecho natural según los principios de la Doctrina de la Ciencia. Traducción de J. Villacañas, F. Oncina y M. Ramos. Madrid: Centro de Estudios Constitucionales. [FDN]

Fichte, J. G. (1997). Filosofía de la masonería. Traducción de F. Oncina Coves. Madrid: Istmo. [FM]

Fichte, J. G. (1998). Sobre la esencia del sabio y sus manifestaciones en el dominio de la libertad. Traducción de A. Ciria. Madrid: Tecnos. [SES] 
Fichte, J. G. (2002). Algunas lecciones sobre el destino del sabio. Edición bilingüe, Traducción de F. Oncina Coves - M. Ramos. Madrid: Istmo. [DS]

Fichte, J. G. (2005). Ética. Traducción de J. Rivera de Rosales. Madrid: Akal. [E]

Fichte, J. G. (2017). Lecciones de filosofía aplicada. Doctrina del Estado. Traducción de S. Turró. Salamanca: Sígueme. [LFA]

\section{Bibliografía secundaria:}

Altman, M. (2008). The significance of the other in moral education: Fichte on the birth of subjectivity. History of Philosophy Quarterly, 25(2), 175-186.

Bacin, S. (2009). "Filosofía aplicada: la idea de Fichte para una nueva Universidad". Traducción de L. Rivera León. En: Oncina Coves, F. (ed.). Filosofía para la Universidad, filosofía contra la Universidad. (De Kant a Nietzsche). Madrid: Universidad Carlos III - Dykinson, pp. 199-232.

Balibar, E. (2011). Fichte y la frontera interior. A propósito de los Discursos a la nación alemana. Traducción de A. Martínez Rodríguez y F. Remiro Elía. La Torre del Virrey: revista de estudios culturales, 10, 11-23.

Baumann, U. (2011). „Der Staat und das Volk. Fichtes politischer Nationalismus“. En: Zöller, G. (Hrsg.). Der Staat als Mittel zum Zweck. Fichte über Freiheit, Recht und Gesetz. Baden - Baden: Nomos, pp. 169-187.

Gaudio, M. (2017). La génesis de la intersubjetividad en la Reivindicación de Fichte. Thémata. Revista de filosofía, 56, 83-102.

Heinz M. - Binkelmann C. (2012). „der innigste Vereinungspunct der Natur und der Vernunft“. Untersuchungen zu Fichtes Eherechts. En Heinz M. - Doyé S. (Hrsg.). Geslechterordnung und Staat. Legitimationsfiguren des politischen Philosophie (1600-1850). Deutsche Zeitschrift für Philosophie $n^{\circ} 27$. Berlín, pp. 251-270.

Hoffmann, T. S. (2019). Libertad hablada. Sobre las dimensiones teórico y pragmáticolingüísticas de la filosofía del lenguaje de Fichte. Ideas, revista de filosofía moderna y contemporánea, 9, 14-33.

Oncina Coves, F. (2019). Fichte como educador. Argumenta philosophica. 1, Barcelona: Herder, 37-52.

Piché, C. (2005). Fichte, Schleiermacher y W. von Humboldt, sobre la creación de la Universidad de Berlín. Traducción de J. M. Cuartas R. Praxis filosófica, nueva serie, 21, 129-155.

Rivera de Rosales, J. (2015). Fichte. La libertad es el fundamento del conocimiento y de la moral. Barcelona: RBA.

Senigaglia, Ch. (2015). „Geist und Natur in Fichtes Ethik“. En: H. Girndt (Hrsg.). »Natur in der Transzendentalphilosophie. Berlín: Duncker \& Humblot, pp. 201217.

Taver, K. (2012), Fichtes Bildungsideal in den Reden an die deutschen Nation (1808) und der Rückgriff auf Pestalozzis. Fichte-Studien, 36, 417-429. 
Traub, H. (2011). „Der Staat und die Erziehung. Die Entstehung von Fichtes staatsund erziehungsphilosophischem Denken aus dem Geist seiner frühen Predigten“. En: G. Zöller (Hrsg.). Der Staat als Mittel zum Zweck. Fichte über Freiheit, Recht und Gesetz. Baden-Baden: Nomos, pp. 133-168.

Williams, R. R. (1992). Recognition. Fichte and Hegel on the Others. New York: State University of New York Press.

Recebido em: 29.03.2020

Aceito em: 09.06.2020

Esta obra está licenciada com uma Licença Creative Commons Atribuição-NãoComercial-

-Compartilhalgual 4.0 Internacional.

https://creativecommons.org/licenses/by-nc-sa/4.0/

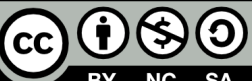

